\title{
The Life's Limitations of Uncontrolled Asthma in a Developing Country: Results of an Albanian Survey
}

\author{
Fatmira Xhixha ${ }^{1, \#}$, Enkeleda Gjata ${ }^{2, \#}$, Mirela Hitaj ${ }^{3}$, Alketa Hysni Bakiri ${ }^{4}$, Entela Hyso ${ }^{5}$, Alkerta \\ Ibranji $^{6}$, Kastriot Shytaj ${ }^{7}$, Arben Ndreu ${ }^{8}$, Bashkim Resuli ${ }^{9}$ and Ervin Çerçiz Mingomataj ${ }^{6,7, *}$

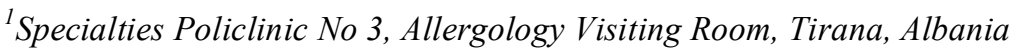 \\ ${ }^{2}$ District Hospital, Allergology Visiting Room, Lushnja, Albania \\ ${ }^{3}$ Specialties Policlinic No 1, Allergology Visiting Room, Tirana, Albania \\ ${ }^{4}$ Albanian University, Faculty of Medical Sciences, Department of Preclinical Disciplines, Tirana, Albania \\ ${ }^{5}$ Regional Hospital, Allergology Visiting Room, Vlora, Albania \\ 6"Mother Theresa" School of Medicine, Department of Allergology \& Clinical Immunology, Tirana, Albania \\ ${ }^{7}$ University of Tirana, Faculty of Technical Medical Sciences, Department of Preclinical Disciplines, Tirana, Albania \\ 8"Mother Theresa" School of Medicine, Department of Infectious Diseases, Tirana, Albania \\ 9"Mother Theresa" School of Medicine, Department of Internal Medicine, Tirana, Albania
}

\begin{abstract}
Introduction: Studies conducted across Western Europe reported that bronchial asthma (BA) has an important impact on patients' lives quality. We present Albanian asthmatic patients' views based on the questionnaire generated from the European Federation of Allergy and Airways Diseases Patients Associations (EFA).

Materials and methodology: In this study participated 145 Caucasian patients consecutively and prospectively diagnosed with BA.

Results: The vast majority of patients reported lifestyle' limitations because of uncontrolled BA, three-fourth of them reported restriction of physical activity, and $20 \%$ felt their professional perspectives were limited. Additionally, up to $80 \%$ of the subjects were not optimistic about achieving the guideline goals but they were optimistic regarding the availability of more qualitative medicines and improvement of healthcare level over the next years. Our patients indicated that optimal treatments should be fast-acting and long-lasting, should be working immediately and should stop the symptoms completely.

Conclusions: These results demonstrate the high impact of uncontrolled asthma, despite its severity, on .patients' lives in a developing country.
\end{abstract}

Keywords: Bronchial asthma, EFA-questionnaire, views of Albanian patients.

\section{INTRODUCTION}

Bronchial asthma (BA) has a great impact on patients' life quality, and many patients consider their disease as a serious health problem $[1,2]$. Many surveys conducted in western countries indicate that severe BA is still not adequately controlled and that asthmatics' management is inefficient [2]. However, this is not necessarily the case for all asthmatic subjects. BA is controllable when patients adhere to the correct treatment according to respective management guidelines [3-5]. In industrialized countries, severe persistent BA is associated with a particularly high exacerbation's risk,

*Address correspondence to this author at the "Mother Theresa" School of Medicine, Department of Allergology \& Clinical Immunology, Tirana, Albania; Tel: ++35542427010; Fax: ++35542229203;

E-mail: allergology@gmx.de

"Both authors contributed equally to this work hospitalization, and death rate. All the above indicate for an impaired life quality as well as a pessimistic outlook towards their BA management $[2,6,7]$.

Most surveys across Europe provide data from industrialized or advanced developing countries, but there is a lack of published data from countries with poor socio-economical situation of the same regional and ethnic populations [2, 5, 711]. We report about the outcomes of an Albanian survey, focused on the opinions of subjects with uncontrolled BA, providing also insight into the level of their lives affection. Albanian is located in the southeastern Europe but is the country with the lowest income in the continent.

\section{MATERIALS AND METHODOLOGY}

Selection of subjects: Patients enrolled in this study had persistent asthma consecutively and prospectively diagnosed 
during November 2008 in three Albanian outpatient centers. Clinical symptoms and respiratory test results were the means used to define BA. The reversibility of bronchial obstruction after inhalation of $200 \mu \mathrm{g}$ salbutamol (increase of forced expiratory flow $>15 \%$ or at least $200 \mathrm{ml}$ ) was considered as an adequate criteria of BA. Patients with suspicious clinical symptoms but normal respiratory test underwent methacholine challenge test. Severe BA in our study was the occurrence of at least one of the asthma symptoms such as wheezing, sleep disturbance, or speech-limiting attacks at least once a week. Uncontrolled (moderate) BA was the occurrence of one of the above symptoms equal or higher than once a month. The occurrence of one of the symptoms less frequent corresponded to well controlling BA.

Questionnaire development: The resultant structured questionnaire is an adjusted translation in Albanian language of a 21-items questionnaire. Multicentre survey conducted in five industrialized European countries by the European Federation of Allergy and Airways Diseases Patients' Associations (EFAa) utilized the same questionnaire [2]. Supervising allergist guided the data collection

\section{RESULTS}

Enrolled patients: All patients (87 f, $58 \mathrm{~m}$ ) confirmed a previous BA diagnosis and 135 of them were under preventative treatment at the time of survey. Their age ranged from 13 to 79 years - mean 48.8 - 95\% confidence interval (CI) 46-51.6, while their BA lasted from 3 to 45 years - mean 22.2, CI 20.2-24.2. Out of 145 patients, 29 were employed, 62 retired, 16 students, and the rest (38) unemployed. Twenty-four patients were active smokers, while 67 subjects were passive smokers.

Asthma control: Classification of uncontrolled (moderate) or severe asthma was based on three questions as described on the methodology. To determine if patients had uncontrolled (moderate) or severe BA or none, they were asked three questions as described in method [2]. More than two-thirds of patients reported disturbed sleeping over the year: 1) at least once a week in about $52 \%$ of the patient, 2) more than once a month in $19 \%$ of subjects. For about one in five patients $(19 \%)$, the severity of their nighttime symptoms was more problematic, with their sleep being disturbed more often than one night a week. Wheezing attacks were also a problem for a greater proportion of asthmatic patients. Nearly three in four patients (about $72 \%$ ) experienced attacks of wheezing at least once a week, while about $8 \%$ of subjects more often than once a month. Speech-limiting attacks occurred at least once a week for each one person out of three (about $30 \%$ ), and $13 \%$ of subjects at least more than once a month. These data demonstrate that a great majority of patients did not achieve asthma control. The major part of the patients did not visit ER and reliever medication more often than once a month scores around $10 \%$. Despite the majority of patients did not visit Emergency, only about $10 \%$ of them did not use reliever medication more often than once a month.

The majority of patients considered BA as annoying and embarrassing, while a considerable part of them stigmatized this pathology as burdensome, stressful, and anxiety provoking. Other negative considerations stated by less than onefifth of patients, while any negative consideration expressed
Table 1. Negative Words Used by Asthmatics to Describe their Asthma

\begin{tabular}{|l|c|}
\hline \multicolumn{1}{|c|}{ Negative Word } & Patients, \% \\
\hline Annoying & 70.3 \\
\hline Burdensome & 35 \\
\hline Stressful & 32.4 \\
\hline Anxiety provoking & 27.6 \\
\hline Frustrating & 9 \\
\hline Frightening & 4.8 \\
\hline Expensive & 17.9 \\
\hline Time consuming & 4.1 \\
\hline Embarrassing & 56.6 \\
\hline Life threatening & 19 \\
\hline None of these & 2.8 \\
\hline
\end{tabular}

Table 2. Activities Missed Out by Asthmatics

\begin{tabular}{|l|c|}
\hline \multicolumn{1}{|c|}{ Thing Missed Out } & Patients, \% \\
\hline \hline Physical activities with friends and family & 75.9 \\
\hline Pets & 11 \\
\hline Going out with friends & 17.9 \\
\hline Holidays & 16.6 \\
\hline Job opportunities & 20 \\
\hline Joining in a school or college & 3.4 \\
\hline Promotion at work & 4.8 \\
\hline Success at study & 1.4 \\
\hline Public places & 73.8 \\
\hline None of these & 4.8 \\
\hline Don't know & 2.8 \\
\hline
\end{tabular}

only about $3 \%$ of them (see Table 1). BA had an important impact on different activities, predominately on physical activities. Three in four subjects stated that BA limited their physical activities, followed by job opportunities in one-fifth of the interviewed patients (Table 2). Other activities were missed in lower percentages, while about $5 \%$ of patients did not report any activity affection. Three-fourths of patients avoided their exposure on public places because of their BA.

There is a strong agreement among Albanian asthmatics regarding their asthma doctor: a) "Knows a lot about asthma"; b) "Give them enough time to talk about their asthma"; c) "Involves them in making the most important decisions about their asthma"; d) "Takes time to make sure that my medicines are right for my life and my asthma"; and e) "Give them a choice about ways to treat their asthma". Relative patients' proportions vary between about $65 \%$ and $92 \%$, while mean scores rate between 8.5 and 9.6 (see 
Table 3. Patients' Opinion About Doctor Abilities

\begin{tabular}{|l|c|c|}
\hline \multicolumn{1}{|c|}{ Patients' Statement } & Patients \% & Mean Strength Rate (CI) \\
\hline \hline Knows a lot about asthma & 92.4 & $9.6(9.2-10.0)$ \\
\hline Involves me in making the most important decisions about my asthma & 85.5 & $9.2(8.8-9.6)$ \\
\hline Gives me a choice about ways to treat my asthma & 64.8 & $8.5(8.1-8.9)$ \\
\hline Gives me enough time to talk about my asthma & 88.3 & $9.4(9.0-9.8)$ \\
\hline Takes time to make sure that my medicines are right for my life and my asthma & 82.3 & $9.0(8.6-9.4)$ \\
\hline Calls me at least once a year to talk about my asthma & 40.7 & $5.4(4.6-6.2)$ \\
\hline
\end{tabular}

Legend: 10 - strongly agree, 1 - strongly disagree.

\section{Table 4. Asthmatics' Matters Related to Asthma Medicines}

\begin{tabular}{|c|c|}
\hline When Receiving After Prescription & Importance Order, \% (First, Second, Third) \\
\hline b) getting the longest lasting benefit & $20.0,9.7,24.8$ \\
\hline c) taking as little as possible & $6.2,3.4,6.2$ \\
\hline d) getting the quickest benefit & $28.3,6.9,11.7$ \\
\hline e) taking as prescribed & $0.7,0.0,0.7$ \\
\hline g) avoiding embarrassment & $7.6,0.0,0.7$ \\
\hline h) none of these & $1.4,0.0,0.0$ \\
\hline Opinion about "familiarized" asthma medicines & Patients, \% / agreement strength mean rate $(\mathrm{CI})$ \\
\hline a) How often I take it & $22.1 / 7.5(7.1-7.9)$ \\
\hline e) Long-lasting side effects & $27.6 / 7.8(7.4-8.2)$ \\
\hline f) The way I take it (inhaler, pills etc) & $29.0 / 7.6(7.2-8.1)$ \\
\hline g) How quickly it works & $80.7 / 9.2(8.9-9.4)$ \\
\hline h) How completely it stops my symptoms & 84.8 / $9.3(9.0-9.7)$ \\
\hline i) How much it lets me forget about my asthma & 22.8 / $6.9(6.4-7.4)$ \\
\hline Fear reasons related to asthma medicines & Patients, \% / agreement strength mean rate $(\mathrm{CI})$ \\
\hline a) I'm worried about becoming dependent on my asthma medicines & $18.6 / 7.1(6.7-7.5)$ \\
\hline b) I'm worried about the possible side effects of my asthma medicines & 24.8 / $7.5(7.0-7.9)$ \\
\hline
\end{tabular}

Legend: 10 - strongly agree, 1 - strongly disagree.

Table 3). Only the statement if the "doctor checks on BA progress at least once a year" is agreed by a consistent minority of patients (about 41\%, mean score 5.4).

During medical prescription, Albanian asthmatics main concern regarding medical prescription is the occurrence of side effects. Worrying at first about occurrence of potential side effects (about 38\%), followed by how to get the quickest $(28 \%)$ and longest lasting $(20 \%)$ benefit. The most important feature of "familiarized" asthma medicine to about $85 \%$ of patients is considered how completely it stops their symptoms (mean score 9.3), followed by how quickly it works (about 81\%, mean score 9.2 - see Table 4). Other fea- tures were considered as quite important; however, the less important things were considered how oft they take the medicine (about 22\%, mean score 7.5) and how much it lets them forget about their asthma (23\%, mean score only 6.9$)$. In addition, a consistent minority of Albanian asthmatics worry about the lack of medicines' effectiveness (44\%, mean score 7.5), while a lower patients' proportion worry about a potential dependence to medicines (about 19\%, mean score 7.1).

Asthma perspectives: Our patients considered as the most attractive alternative a pill once a month (about 63\%, mean score 9.2) followed by an inhaler once a month (about $61 \%$, 
Table 5: Ideal Medicine Intake and Ways of Asthma Improvement

\begin{tabular}{|l|c|}
\hline \multicolumn{1}{|c|}{ Ideal Method of Medicine Intake } & Patients, \% / Agreement Strength Mean Rate (CI) \\
\hline \hline a) A single inhaler once a day & $23.4 / 6.6(6.2-7.1)$ \\
\hline b) A pill once a day & $19.3 / 6.8(6.3-7.2)$ \\
\hline c) An injection once a day & $0.0 / 2.5(2.1-2.8)$ \\
\hline d) An inhaler once a month & $60.7 / 9.2(8.9-9.5)$ \\
\hline e) A pill once a month & $62.8 / 9.2(8.8-9.6)$ \\
\hline f) An injection once a month & $13.1 / 5.9(5.5-6.3)$ \\
\hline g) A one-off operation or implant & $58.6 / 6.1(5.4-6.8)$ \\
\hline Ways of asthma improvement & \\
\hline a) Better access to asthma specialist when I need one & $77.9 / 8.9(8.5-9.3)$ \\
\hline b) New, more effective medicines & $86.9 / 9.3(9.0-9.7)$ \\
\hline c) Having more influence over my asthma treatment & $47.6 / 7.6(7.1-8.1)$ \\
\hline
\end{tabular}

Legend: 10 - strongly agree, 1 - strongly disagree.

mean score 9.2). Other alternatives reported as less attractive, except the injection once a day considered as quite unattractive (Table 5). Notably, the alternative "a one-off operation or implant" was considered as the third most attractive (61\%), but its mean score (6.1) was comparable to the rest of alternatives. Concerning improvement of BA symptoms, they considered as the most important thing the disposition of new, more effective medicines (about 87\%, mean score 9.3). However, other alternatives were as important (see Table 5).

When considering pathologic symptoms and patients' perceptions actually and in 5 years' time, there was a similarity with respect to BA episodes and long-term symptoms for the two periods chosen. Albanian asthmatics have the most optimistic outlook towards BA actually and in five years only towards the most negative daily experiences. This includes their outlook towards avoidance of emergency visits: two-thirds of them expected that this goal is achievable (about $70 \%$ vs. $66 \%$ ). Thinking about their disease at the actual time, only a minor proportion of Albanian asthmatics expect the achieving of other goals (rates between $23 \%$ and $41 \%$ ). With respect to their achieving expectations in five years time, they believe to avoid or be closely to avoid restrictions in daily activities (about 55\%), whereas the rest of statements about a controlled asthma were considered as realistic, only from the minority of patients (rates between $24 \%$ and $39 \%$ ).

The partially optimistic outlook of Albanian patients is evident when considering the future generation of their asthma drugs' choice and healthcare system (respectively Fig. (1A and 1B). They strongly expect from their government: a) fist to make efforts against environmental pollution (about $86 \%$ ); b) second - to invest in research for new (better) medicines, and c) to provide free prescriptions for asthmatics (both about $68 \%$ ); as well as d) third - to ban smoking in public places $(59 \%$ - see Fig. 2). These requests agree with overall view, which is that the patients' majority are expecting from national authorities to provide better healthcare (about 60\%) and new treatments (about 65\%) in the future (Fig. 1). As shown above in Table 5, these medicines should act as long as possible and be comfortably administered.

\section{DISCUSSION}

This survey provides a realistic insight into how Albanian asthmatics (which live in a European developing country) view their disease and its management, and how this may change in the next five years. Considering their asthma mostly as annoying (70\%) and/or embarrassing (57\%), most subjects complain about limitations to their lifestyles as a consequence of moderate or severe BA: Exercising or physical activities is restricted for three-fourths of patients, and a considerable part of them had the feeling that their professional perspectives were limited (20\%). Additionally, nearly $80 \%$ of mentioned population did not expect the achieving of guideline goals [2]. In comparison to industrialized European countries (IECs), the proportion of patients with uncontrolled or severe BA is quite greater [2, 7]. In Italy, a neighbor land of Albania, among 2853 recruited adult patients, $64 \%$ had controlled BA, $16 \%$ partly controlled BA and only $20 \%$ were with uncontrolled BA [5]. Meanwhile, one-third of patients with respiratory allergic diseases recruited in ten different IECs were not satisfied with their treatment, and two-thirds experienced restrictions in daily activities $[2,7,10]$. No major differences resulted in these countries, regarding the above-mentioned issues. Still, Swedish patients believed they were closer to achieving the guideline goals. This might be due to a better disease management as it was reported frequent preventive treatment in this specific country [2].

Our survey revealed that sixty percent of the enrolled patients were women, $17 \%$ smokers, $46 \%$ ex-smokers, and $26 \%$ unemployed people. Similarly, to our findings, in a Swedish study $58 \%$ of the subjects were women, while $24 \%$ were smokers and 22\% ex-smokers [12]. Determinants of a lower life quality were respiratory symptoms severity, tobacco smoking, being female, and attended by a primary care physician, and absenteeism from school and work [12-14]. 

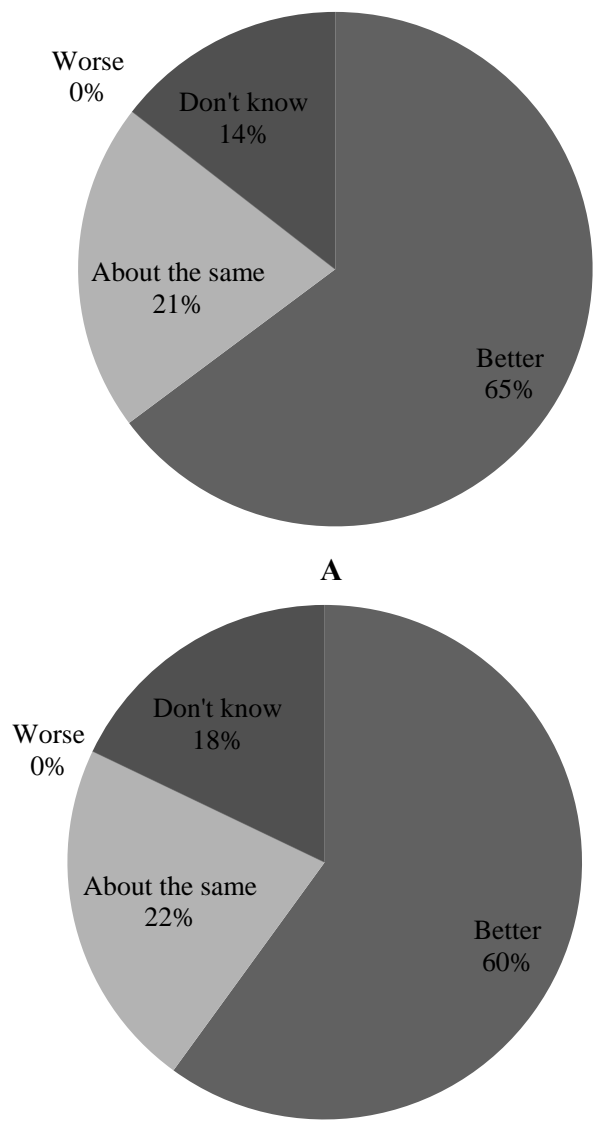

B

Fig. (1). Opinion of Albanian asthmatics over the next five years:

A) The choice of asthma drugs, B) the development of healthcare $(\mathrm{n}=145)$.

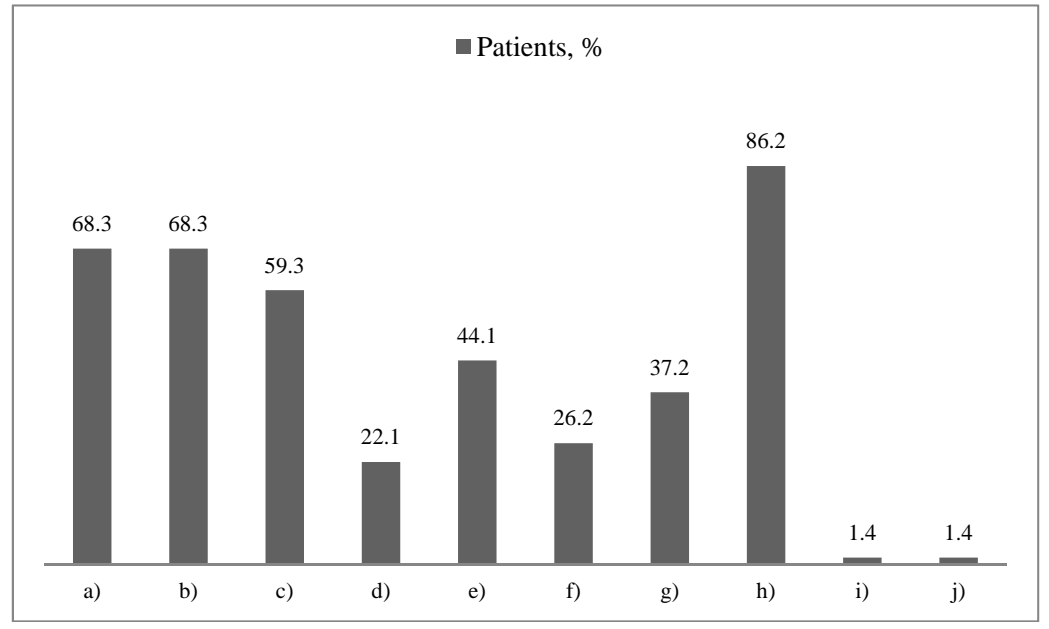

Fig. (2). The interests of Albanian patients towards their government activity for a better asthma management

Legend: a) Invest in research for new asthma treatments; b) Provide free prescriptions for people with asthma; c) Ban smoking in public places; d) Ensure immediate access to an asthma specialist when one is needed; e) Improve public awareness of what to do in an asthma attack; f) Increase public awareness of asthma in adults; g) Provide better information about treatments; h) Decrease pollution/make an effort to fight pollution; i) Other; j) Don't know (n=145).

Asthmatics' attitudes towards their medication play a major part in the disease management [2]. It is important to have a closer look at asthma management of this population in order to understand better the opinions regarding BA management. Drugs of first line used at the time of our study were: beta-agonists salbutamol, formoterol or salmeterol, glucocorticoids beclometasone, flixotide, or budesonide (as inhalator treatment), prednisolone or methylprednisolone (as emergency i.m or i.v. treatment), and xanthine derivatives (p.o or i.v.) The major causes of acute exacerbations and lack of disease control were respiratory infections, usage of insufficient quality marketed medicines on one side and inappropriate usage of them on the other, socio-economic problems, indoor and outdoor harmful environmental exposure (data not shown). 
As demonstrated in our survey, patients preferred medications that are (even more) fast -acting and long -lasting that completely stop the symptoms, and have minimal side effects. The general attitude of Albanian asthmatics shows a similarity towards Europeans with severe BA in the industrialized countries [2-11]. These findings suggest that in our country patients with uncontrolled asthma represent the majority, and that Albanian (predominantly male) patients consider their BA as a disease only if they experience uncontrolled symptoms and daily restrictions. Patients with mild symptoms avoid the medical visits. Consequently, patients with uncontrolled and severe BA interviewed in our study represent a more selective target group compared to reasonable expected results.

Side effects and a lack of a perceived medication effect are probably the major obstacles to the BA management [2, 15]. The majority of Albanian patients worry about potential side effects of prescribed medicines. They were confident with asthma treatment but side effects was the less important concern compared to other medicine properties This findings suggest that, asthmatic patients accepted side effects as necessary and a part of them did not worry about them at all. This is, either because they had not experienced any or because they trusted their doctor [2]. The majority of recruited patients in the International Asthma Patient Insight Research (INSPIRE) study were quite confident in the selfmanagement of the BA, although many were concerned about taking medication when they were free from symptoms [16]. These findings indicate that an active role in the BA management allows patients to allay fears about their medications [2].

An important feature of asthmatics' attitude towards their treatment is that patients should communicate about their opinion and experiences, being therefore involved in the decision-making process. In the absence of their insight, key information may be lacking in future important communications [2, 17]. Improvement of patient understanding is important and it is accomplished by a good relationship between physician and their patients, and many of them take into the account, the interaction they have with their doctor [18]. Albanian patients consider their physician as competent and communicative. On the other side, this study revealed that $60 \%$ of doctors did not follow up their patients. Monitoring and the follow up of patient's health progression resulted as a handicap of BA management even in IECs. This might have an important impact on the BA control, as patients themselves will often try to manage troublesome symptoms [16]. The present survey revealed a high rating (approximately 17 of 20) by patients when asked whether the doctor involve them in making the most important decisions about their asthma, or (approximately 13 of 20) when asked whether their doctor gives them an opportunity to chose their treatment. Similar findings have been published from other EFA-study conducted in five different IECs, in which 7 of 10 patients rated when asked whether their asthma practitioner gives them a choice of treatment [2]. These data suggest that the patient-physician partnership is a contributory factor in the improvement of asthma treatment, and patient education is a key factor per se [11].
This survey confirms that many subjects with moderate or severe BA do not reflect enough optimism about the perspective of asthma management [2]. Different studies support the opinion that the greater the severity of patients' BA, the greater the effect on patients' life quality [7, 19-21]. These results confirmed that wheezing episodes, sleep disturbances, and speech-limiting excesses in asthmatic adults are very frequent, although the prevalence of BA in Albania is the lowest among European countries [22].

Levels of asthma control in subjects with moderate or severe BA are in a status quo not only in our study but across Europe too. This demonstrate that a substantial proportion of asthmatics remain not well-controlled [8]. In 2010, the proportion of treated asthma patients assessed as having not well-controlled asthma was about $54 \%$, compared to $57 \%$ and $55 \%$ in 2008 and 2006, respectively [2,8]. Meanwhile, patients with severe BA complain about high levels of distress and anxiety, about restriction of daily activities and the lack of future perspectives [21, 23, 24]. According to different studies, patients with poorly controlled BA were more frequently women, older, with a worse pulmonary function, obese, more anxious, and/or more depressed [14, 21]. Even across IECs, researchers share the opinion that emotional burden of disease is underappreciated $[9,10,12]$. Respiratory specialists with a special interest in difficult cases will be required to improve management perspectives of subjects with complex BA $[24,25]$. In other words, a better understanding of this association may have major clinical implications mainly in patients with poor controlled BA where the presence of anxiety and depression should be investigated $[14,21]$.

Existence of different opinions and expectations across Europe are understandable, as national authorities and healthcare systems differ [2]. Similarly, to the patients with severe BA that originates from IECs, Albanian patients were generally pessimistic about the future of their BA and national healthcare system. Improvement in management of $\mathrm{BA}$ resulted as essential in their opinion. The association of pessimism with BA is not rare, considering that patients with mild asthma deny visiting the doctor [2]. Nevertheless, the negative mood is an important factor when conducting surveys, as this could potentially influence data that rely on subjective opinion [26].

Similarly, to the EFA-survey, most optimistic opinion stands for generation of more effective therapies in the future [2]. Several available therapies enable improved asthma control in patients with persistent symptoms, which in turn will help improve patients' life quality and allow them to live beyond their limitations [3, 6, 27]. However, in our survey the most optimistic statements are related to the emergency visits and daily activities. The disposition of effective medicaments is a necessary component in the strategy for achieving asthma control, but other factors have been also emerged as essential steps for improving the level of care [2]. Apart from development of more effective medicines, many patients emphasize that accessibility to specialist might help as part of their management program.

National authorities around the world are making enormous efforts in different areas to improve the quality of life for the asthmatic subjects. Healthcare providers should ex- 
plore other novel approaches to decrease the BA-related costs [2]. In the opinion of Albanian asthmatics, more efforts are necessary against pollution and ban smoking in public places. Further efforts on the improvement of asthma management and reduction of BA-related costs should be considered such as providing of free prescriptions for asthmatics and improving of public awareness in handling with an asthma attack. Notably, in a developing country like Albania the proportion of asthmatics that required free prescriptions for medicines was equally to the patients' proportion that required further investments in research for new asthma treatment. It is a fact that in Albania (the European country with the lowest average incomes) free prescriptions are provided for asthmatic invalids or retired peoples only for some traditional medicines. Considering that, we were likely to expect that the free prescriptions requiring proportion were much greater than researching for new treatment requiring proportion. In contrast to Albanian asthmatic populations, patients with severe BA in the IECs share the opinion that introduction of self-management plans, internet-based education, and use of mobile telephones to improve communication between patients and healthcare professionals might facilitate improvements in asthma control and subsequently help reduce cost [28-32]. The implementation of new policies and written action plans may contribute to reduction of the economic burden; however, not all patients benefit from them even in the IECs [33-35]. The requests of Albanian asthmatics indicate the great effort expected to reach the healthcare level provided in the IECs, as a contributing factor towards ineffective asthma control.

\section{CONCLUSIONS}

In addition to IECs results, in developing countries like Albania, besides severe phenotype even the moderate form of BA has an equally important impact among patients. BA restricts their daily activities, causes embarrassment, or imparts fear, becoming a major burden on healthcare system. Moreover, insufficient information and a lack of understanding about drugs' side effects can often lead to non-adherence to treatment, and consequently to inadequate asthma control [36]. The inefficiencies in the management of this population indicate that much effort in achieving guideline goals is necessary. Like across Europe, perceptions towards BA and expectations for the future differ from one patient to another, and understandably, many of them do not reflect optimism about the future of BA management $[2,8]$. They share a positive opinion about the generating of new medicines to help symptoms control of persistent BA. Patients believed that national healthcare investment in novel strategies, improving surveillance, collaborating to understand their needs, and the generating of new medications to facilitate the treatment of moderate and severe asthma phenotypes will give them hope that someday they might have a limitations-free life even in a developing country like Albania.

\section{CONFLICT OF INTEREST}

The authors confirm that this article content has no conflicts of interest.

\section{ACKNOWLEDGEMENT}

\section{REFERENCES}

[1] Yawn BP, Fryer GE, Lanier D. Asthma severity: the patient's perspective. J Asthma 2004; 41: 623-30.

[2] Dockrell M, Partridge MR. Valovirta E. The limitations of severe asthma: the results of a European survey. Allergy 2007; 62: 134-41.

[3] Global Initiative for Asthma (GINA). Global Strategy for Asthma Management and Prevention NIH Publication No 02-3659 Issued January 1995 (updated 2005). Available at http://www.gina asthma.org.

[4] British Thoracic Society, Scottish Intercollegiate Guidelines Network. British guideline on the management of asthma. Thorax 2003; 58(Suppl 1): i1-i94.

[5] Allegra L, Cremonesi G, Girbino G, et al. Real-life prospective study on asthma control in Italy: cross-sectional phase results. Respir Med 2012; 106: 205-14.

[6] Peters SP, Ferguson G, Deniz Y, Reisner C. Uncontrolled asthma: A review of the prevalence, disease burden and options for treatment. Respir Med 2006; 100: 1139-51.

[7] Chivato T, Valovirta E, Dahl R, et al. Allergy, living and learning: diagnosis and treatment of allergic respiratory diseases in Europe. $\mathrm{J}$ Invest Allergol Clin immunol 2012; 22: 168-79.

[8] Demoly P, Annunziata K, Gubba E, Adamek L. Repeated crosssectional survey of patient-reported asthma control in Europe in the past 5 years. Eur Respir Rev 2012; 21: 66-74.

[9] Siroux V, Boudier A, Bousquet J, et al. Asthma control assessed in the EGEA epidemiological survey and health-related quality of life. Respir Med 2012; 106: 820-8.

[10] Partridge MR, Dal Negro RW, Olivieri D. Understanding patients with asthma and COPD: insights from a European study. Prim Care J Med 2011; 20: 315-23.

[11] Small M, Vickers A, Anderson P, Kay S. The patient-physician partnership in asthma: real-world observations associated with clinical and patient-reported outcomes. Adv Therapy 2010; 27: 591-9.

[12] Leander M, Lampa E, Janson C, Svärdsudd K, Uddenfeldt M, Rask-Andersen A. Determinants for a low health-related quality of life in asthmatics. Ups J Med Sci 2012; 117: 57-66.

[13] Kauppi P, Kupiainen H, Lindqvist A, et al. Overlap syndrome of asthma and COPD predicts low quality of life. J Asthma 2011; 48: 279-85.

[14] Badiola C, Badiella L, Plaza V, et al. Women, patients with severe asthma, and patients attended by primary care physicians, are at higher risk of suffering from poorly controlled asthma. Prim Care Respir J 2009; 18: 294-9.

[15] Boulet LP. Perception of the role and potential side effects of inhaled corticosteroids among asthmatic patients. Chest 1998; 113: 587-92.

[16] Partridge MR, Molen TV, Myrseth SE, Busse WW. Attitudes and actions of asthma patients on regular maintenance therapy: the INSPIRE study. BMC Pulm Med 2006; 6: 13.

[17] Raynor DK, Savage I, Knapp P, Henley J. We are the experts: people with asthma talk about their medicine information needs. Patient Educ Couns 2004; 53: 167-74.

[18] Trollvik A, Severinsson E. Parents' experiences of asthma: process from chaos to coping. Nurs Health Sci 2004; 6: 93-9.

[19] Juniper EF, Wisniewski ME, Cox FM, Emmett AH, Nielsen KE, O'Byrne PM. Relationship between quality of life and clinical status in asthma: a factor analysis. Eur Respir J 2004; 23 : 287-91.

[20] Horak E, Sawyer SM, Roberts M, et al. Impact of disease severity on quality of life in adults with asthma. Wien KlinWochenschr 2005; 117: 462-7.

[21] Di Marco F, Verga M, Santus P, et al. Close correlation between anxiety, depression, and asthma control. Respir Med 2010; 104: 228.

[22] European Community Respiratory Health Survey (ECRHS). Variations in the prevalence of respiratory symptoms, self-reported asthma attacks, and use of asthma medication in the European Community Respiratory Health Survey (ECRHS). Eur Respir J 1996; 9: 687-95.

Vamos M, Kolbe J. Psychological factors in severe chronic asthma. Aust N Z J Psychiatry 1999; 33: 538-44.

Mingomataj EÇ, Bakiri AH. The role of neuroimmune and psychological systems in the pathophysiology of bronchial asthma. In: Bislimi A, Tolka L, Eds, Asthma: causes, complications and

Declared none. 
treatment. New York: Nova Science Publishers Inc 2012; pp. 3360 .

[25] Roberts NJ, Robinson DS, Partridge MR. How is difficult asthma managed? Eur Respir J 2006; 28: 968-73.

[26] Ekici A, Ekici M, Kara T, Keles H, Kocyigit P. Negative mood and quality of life in patients with asthma. Qual Life Res 2006; 15: 4956.

[27] Humbert M, Beasley R, Ayres J, et al. Benefits of omalizumab as add-on therapy in patients with severe persistent asthma who are inadequately controlled despite best available therapy (GINA 2002 step 4 treatment): INNOVATE. Allergy 2005; 60: 309-16.

[28] Kamps AW, Roorda RJ, Kimpen JL, Overgoor-van de Groes AW, van Helsdingen-Peek LC, Brand PL. Impact of nurse-led outpatient management of children with asthma on healthcare resource utilisation and costs. Eur Respir J 2004; 23: 304-9.

[29] Runge C, Lecheler J, Horn M, Tews JT, Schaefer M. Outcomes of a Web-based patient education program for asthmatic children and adolescents. Chest 2006; 129: 581-93.
[30] Ostojic V, Cvoriscec B, Ostojic SB, Reznikoff D, Stipic-Markovic A, Tudjman Z. Improving asthma control through telemedicine: a study of short message service. Telemed J E Health 2005; 11: 2835.

[31] Ryan D, Cobern W, Wheeler J, Price D, Tarassenko L. Mobile phone technology in the management of asthma. J Telemed Telecare 2005 ; 11(Suppl. 1): 43-6.

[32] Amado MC, Portnoy JM. Recent advances in asthma management. Mol Med 2006; 103: 60-4.

[33] de Asis ML, Greene R. A cost-effectiveness analysis of a peak flow-based asthma education and self-management plan in a highcost population. J Asthma 2004; 41: 559-65.

[34] Action plans in asthma. Drug Ther Bull 2005; 43: 91-4.

[35] Haughney J, Barnes G, Partridge M, Cleland J. The Living \& Breathing Study: a study of patients' views ofasthma and its treatment. Prim Care Respir J 2004; 13: 28-35.

[36] Barber N, Parsons J, Clifford S, Darracott R, Horne R. Patients' problems with new medication for chronic conditions. Qual Saf Health Care 2004; 13: 172-5.

(C) Xhixha et al.; Licensee Bentham Open.

This is an open access article licensed under the terms of the Creative Commons Attribution Non-Commercial License (http://creativecommons.org/licenses/by-nc/3.0/) which permits unrestricted, non-commercial use, distribution and reproduction in any medium, provided the work is properly cited. 